\title{
Use of Placebos and Nonspecific and Complementary Treatments by German Physicians - Rationale and Development of a Questionnaire for a Nationwide Survey
}

\author{
Klaus Linde ${ }^{a}$ Clara Friedrichs $^{a} \quad$ Anna Alscher ${ }^{a}$ Wolfgang A. Blank $^{a} \quad$ Antonius Schneider $^{a}$ \\ Margrit Fässler $^{\mathrm{b}}$ Karin Meissner ${ }^{\mathrm{c}}$ \\ ${ }^{a}$ Institut für Allgemeinmedizin, Klinikum rechts der Isar, Technische Universität München, Germany \\ ${ }^{b}$ Institute of Biomedical Ethics, University of Zurich, Switzerland \\ ${ }^{c}$ Institute of Medical Psychology, Ludwig-Maximilians-University, Munich, Germany
}

\author{
Keywords \\ Placebos · Placebo effect · Complementary therapies . \\ Cross-sectional study · Germany
}

\section{Summary}

Background: We are performing a nationwide survey in a random sample of German general practitioners (GPs), orthopedists, and internists on the use of placebos and nonspecific as well as complementary treatments and their association with basic professional attitudes. In this article we explain the theoretical considerations behind the study approach and the development of the questionnaire. Methods: Based on a systematic review of published surveys, own surveys on the topic, and on theoretical considerations we developed a preliminary version of a 4-page questionnaire that was tested for feasibility in a convenience sample of 80 participants of a general medical education event. We also performed cognitive interviews with 8 physicians to investigate whether the questions were understood adequately. Results: The questions on typical placebos and complementary treatments were well understood and easy to answer for participants. Discussions about the phrasing of questions on nonspecific treatments during interview reflected the vagueness of this concept; but this did not seem to create major problems when answering the related questions. The original questions regarding basic professional attitudes partly were not understood in the manner intended. The relevant questions were modified but the interviews suggest that these issues are difficult to grasp in a quantitative survey. Conclusion: Our testing procedures suggest that our questionnaire is well-suited to investigate our questions with some limitations regarding the issue of basic professional attitudes.

\author{
Schlüsselwörter \\ Placebos · Placeboeffekt · Komplementäre Therapien · \\ Querschnittstudie · Deutschland
}

\section{Zusammenfassung}

Hintergrund: Die Autoren führen derzeit eine Befragung einer Zufallsstichprobe niedergelassener Allgemeinmediziner, Orthopäden und Internisten in Deutschland durch. Erhoben wird die Verwendung von Placebos sowie unspezifischen und komplementären Therapien und damit verbundenen berufsethischen Grundhaltungen. Im vorliegenden Artikel werden die theoretischen Hintergründe und die Entwicklung des verwendeten Fragebogens dargestellt. Methoden: Basierend auf einem systematischen Review veröffentlichter Umfragen, eigenen Erhebungen zu diesem Thema und theoretischen Überlegungen wurde eine vorläufige Version eines 4-seitigen Fragebogens entwickelt und 80 Teilnehmern einer allgemeinmedizinischen Fortbildungsveranstaltung vorgelegt. Zusätzlich wurden kognitive Interviews mit 8 Ärzten durchgeführt, um das Verständnis der Fragen qualitativ zu überprüfen. Ergebnisse: Die Fragen zu typischen Placebos und komplementären Verfahren wurden problemlos verstanden und beantwortet. Die Formulierung der Fragen zu unspezifischen Therapien führte regelhaft zu Diskussionen, die die Unklarheit dieses Konzepts reflektierten; dies schien jedoch nicht zu größeren Verständnisproblemen bezüglich der Beantwortung daran anlehnender Fragen zu führen. Ein Teil der Fragen zu berufsethischen Grundhaltungen wurde dagegen teilweise nicht in der von uns intendierten Weise verstanden. Die relevanten Fragen wurden zwar modifiziert, aber die Interviews legen nahe, dass die entsprechenden Informationen mit standardisierten Fragebögen nur eingeschränkt erfassbar sind. Schlussfolgerung: Die Prüfverfahren sprechen dafür, dass unser Fragebogen für die Erreichung der Studienziele insgesamt gut geeignet ist, obgleich sich die berufsethische Grundhaltung nur schwer quantitativ erfassen lässt.

\section{KARGER \\ Fax +497614520714 \\ Information@Karger.com}

www.karger.com (c) 2013 S. Karger GmbH, Freiburs

$1661-4119 / 13 / 0205-0361 \$ 38.00 / 0$

Accessible online at

www.karger.com/fok 


\section{Introduction}

Surveys on the use of placebo interventions have shown that between 17 and $80 \%$ of physicians have applied 'pure' placebos (treatments which are devoid of any intrinsic activity, e.g., sugar tablets or saline injections) at some point during their professional life [1]. The actual frequency of the use of pure placebo seems, however, to be rare. Outside hospital walls the use of so-called 'impure' placebos is much more frequent [1]. The term impure placebos is used in the academic discussion to denote treatments thought to be active in principle, but considered to have no activity over placebo in the actual patient being treated; e.g., an antibiotic for uncomplicated upper respiratory tract infection. Exact estimations how frequently such interventions are used are difficult as definitions of when a treatment becomes an impure placebo are variable and underlie subjective interpretations [1]. As the concept of impure placebo is not intuitively understood by practising physicians in Germany and might be misleading $[1,2]$ we likewise use the term nonspecific treatments in this article, although this term is problematic, too.

While the German Medical Association recently published a detailed state of the art report on placebo in research, practice, and legal issues [3] little is known about the actual use of such therapies in Germany. Two studies published in 1981 [4] and 2009 [5] investigated the application of pure placebos in hospitals. Both studies provide evidence that pure placebos have been applied by many physicians, however, in rare instances. Our own group recently sent a questionnaire about placebo use to 400 general practitioners (GPs) in Bavaria [6]. The response rate was $55 \%$ with $45 \%$ of responding GPs having used pure placebos in the last year (median frequency 5 , interquartile range $2-10$ ). $76 \%$ reported that they had used impure placebos at least once during the last year, with a median frequency of 20 times per year (interquartile range 1050). When asked for reasons for the use of placebos physicians most often chose the following options from a predefined list: a psychological effect (reported by $77 \%$ of pure placebo users and $79 \%$ of impure placebo users), the expectations of patients to receive a treatment (57 and 52\%), the handling of difficult treatment situations (47 and $46 \%$ ), offering an additional treatment option to suffering patients (19 and 47\%), and nonspecific complaints (42 and 31\%). There is no data available on the use of placebo interventions by German physicians specialized in other fields.

We decided to perform a nationwide survey in a random sample of GPs, orthopedists, and internists on the use of placebos as well as nonspecific and complementary treatments and their association with basic professional attitudes. We are not aware of other studies that tried to link these subjects in the way we do, so we hope that our survey will be able to provide new insights. In this article we explain the theoretical considerations behind our approach and the development of our questionnaire.
Theoretical Considerations for Questionnaire Development

While most published placebo surveys include questions on reasons and motives for the use of placebos and nonspecific treatments authors rarely discuss on a conceptual level why physicians use such interventions. It seems that many survey authors implicitly think that eliciting placebo effects is a major motive and that the use of placebo interventions would be legitimate if the patient would not be deceived. Instead, our central assumption is that impure placebos / nonspecific treatments are applied to deal with uncertain and difficult situations in clinical practice. This assumption is based on a number of qualitative investigations exploring reasons why physicians sometimes use interventions they do not consider active or adequate. In a study by Comaroff [7] published in 1976 the attitudes of 51 GPs in Wales toward placebos and nonspecific treatments were surveyed indirectly, in the context of a more general discussion about prescribing behavior. Practitioners were first asked to estimate the proportion of their consultations culminating in a treatment prescription. All participants set the proportion at $70 \%$ or higher. In their elaborate answers, most practitioners spontaneously stated that they did not consider all prescriptions as truly necessary and felt necessitated to provide justifications. Implicitly the answers clearly indicated that the physicians had internalized a professional ideal requiring that any treatment should be specific in effect and administered or prescribed only when necessary. However, this ideal conflicted with the realities of GPs in routine practice. Seeing only unselected patients, GPs faced considerable uncertainty but still needed to make decisions. On the one hand, making a firm diagnosis in general practice was often impossible or unnecessary, implying that the basis for choosing a specific treatment was weak. On the other hand, physicians usually believed that patients expected a clear diagnosis and a treatment. Therefore, the GPs often used nonspecific treatments.

Research on difficult prescribing situations also suggests that ideals and self-perception of physicians might be more important reasons for prescribing placebos or nonspecific treatment than the triggering of placebo effects. Henriksen and Hansen [8] interviewed 20 GPs to investigate their selfperception in relation to prescribing medicine. The study focused on threats to the self-image in a general manner, but clearly nonspecific interventions played a major role. Also this study found that an orientation towards human or scientific ideals was implicitly fundamental to the physicians. However, multiple factors made it difficult to live up to the ideals. Due to patient demand, lack of time or the need to do any kind of treatment physicians gave prescriptions against their convictions in given situations. To be able to face themselves in the mirror physicians developed strategies to protect themselves. They tried to set the ideals realistically, take a stand, and believe in themselves. A qualitative study by Weiss and Scott [9] suggests that nonspecific interventions (called 'irrational prescribing' in the paper) and prescribing in general are seen as a problem-solving tool which can be used to manage a variety of 
difficult situations in routine practice. They argue that such prescribing behavior, while being considered irrational from a medico-scientific perspective, is rational in the broadest sense of problem-solving acknowledging the humanity of the therapeutic relationship. This challenges the usual definition of rational prescribing. Further, qualitative studies on the inadequate prescription of antibiotics in case of sore throats or colds $[10,11]$ found even more evidence suggesting that GPs do not apply nonspecific interventions mainly to trigger placebo effects. In these studies the word placebo or the idea of triggering placebo effects did not come up at all while surveys on the use of placebo often consider this as a typical example of a placebo prescription [1].

Compared to other specialties, the use of nonspecific interventions or impure placebos seems to be particularly widespread among GPs [1, 6, 12-14]. This is plausible when considering that GPs see many patients with complaints not easy to diagnose precisely [15] and who have minor ailments [16]. We would expect that for specialists of internal medicine who mainly see preselected cases with more advanced disease and clear diagnoses receiving multiple treatments, the use of impure placebo is less often an option. We speculate that orthopedic specialists in private practice are a particularly interesting group with respect to our subject but we are not aware of any studies investigating placebo use among this group. Orthopedists are trained in hospitals with strong emphasis on surgical techniques while in private practice they see a lot of patients with relatively nonspecific complaints [17]. One could therefore assume that orthopedists often feel strong uncertainty towards their patients and do not have straightforward evidence-based treatment options. Thus, we would expect that they use nonspecific treatments less often than GPs but more often than specialists in internal medicine.

We hypothesize that there should also be a relation between the use of complementary and alternative treatments (such as herbal medicine, acupuncture, homeopathy, chiropractic or osteopathy) and nonspecific treatments. Complementary medicine offers, or seems to offer, 'specific' diagnostic and therapeutic solutions for many patients for whom conventional medicine does not provide satisfactory answers. Believing in the efficacy and using complementary treatments could therefore be a way of reducing uncertainty and keeping professional ideals (while maybe implying some conflict with professional orthodoxy). If this proved true, one should expect that providers of complementary treatments have less need for using treatments they personally consider to be nonspecific. At the same time we think that convinced providers of complementary treatments also believe in a strong mind-body connection and strong placebo effects. One could therefore assume that they are more open towards the use of placebo interventions. Finally, a consistent finding in surveys from Germany and Switzerland is that many physicians use complementary treatment as impure placebos / nonspecific intervention $[6,13,18]$. It would be interesting to know whether these physicians have sceptic attitudes towards complementary medicine.

Based on the considerations summarized above, we would like to test the following hypotheses:

1. We expect that in all 3 groups (GPs, internists, and orthopedists) impure placebos / nonspecific interventions are used broadly and more frequently than pure placebos.

2. GPs use impure placebos / nonspecific interventions and complementary therapies more often than physicians specialized in internal medicine.

3. Orthopedists use impure placebos / nonspecific interventions and complementary therapies more often than internists (although we are somewhat uncertain whether orthopedists are willing to classify their actions in that way).

We will also investigate whether characteristics of physicians (regardless of specialization) using pure placebos only, using nonspecific therapies only or using both placebos and nonspecific therapies differ from those reporting to neither use pure placebos nor nonspecific interventions. We did not formulate explicit hypotheses regarding associations between basic professional attitudes and the frequency of impure placebo use, as we are uncertain whether our quantitative survey will truly grasp professional attitudes in a sufficiently valid manner. We believe that the true reasons for the use of impure placebos / nonspecific interventions should mainly be investigated using qualitative methods (therefore, we also aim to perform such a study). Nevertheless we will try to investigate the association between statements regarding some basic professional attitudes based on the considerations above and the use of such interventions.

\section{Methods of Questionnaire Development}

Based on our systematic review of surveys [1], our previous survey [6], informal discussions with GPs, and the theoretical considerations summarized above we developed a pilot version of a questionnaire. The pilot version was then handed out at a continuing education event for GPs to about 120 participants of whom 80 returned the completed questionnaires (pretest). Participants were asked to give their comments on the questionnaire on the last page. Based on the results of this pretest we slightly modified the questionnaire. Then a total of 7 so-called cognitive interviews with 8 physicians ( 4 general practitioners, 3 internists, and 1 orthopedist; duration between 34 and $90 \mathrm{~min}$ ) were performed to check whether physicians understood the questions in the way intended by the investigators. In survey research such interviews are performed to understand the cognitive processes when individuals answer questions [19]. The main technique used was probing (asking additional questions to check whether physicians had understood items in the way intended). Physicians were first asked to fill in the questionnaire. They were asked to do it in the same speed as if they would do when participating in a postal survey. The interviews then were performed according to a semi-structured guideline allowing considerable flexibility. Areas of particular interest were how physicians understood the terms placebo and nonspecific therapies, and whether physicians understood some more difficult questions regarding their attitudes. Interviews were recorded with audio tape. The audio tapes were analyzed independently by 2 investigators and summarized in protocols. If interviews showed obvious problems with specific questions 


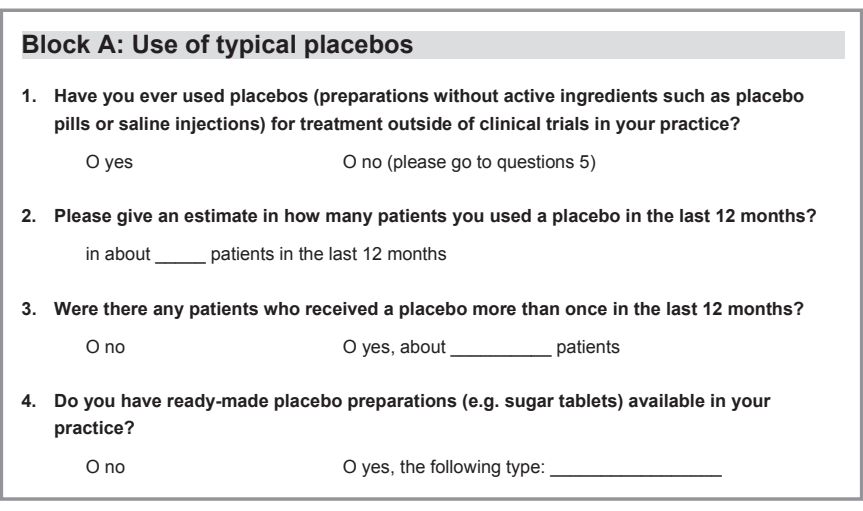

Fig. 1 A. Use of typical placebos.

these were modified before the following interviews. The interview phase led to some slight changes of the wording of the questions on the use of pure placebos and nonspecific interventions and to some more profound changes of the questions on professional attitudes in the final version of the questionnaire.

\section{Results}

The final questionnaire consists of 50 questions on 4 pages and is divided in 5 blocks. Block A (fig. 1 A) consists of 4 questions on the use of 'typical' placebos (defined as 'preparations without active ingredients such as placebo pills or saline injections'): use, number of patients who received placebo in the last 12 months, number of patients who received a placebo on more than one occasion, and availability of readymade placebo preparations (e.g., sugar pills) in practice. These questions had been included in our previous survey [6] but were modified slightly based on experiences from the survey and the cognitive interviews. For example, in the previous survey $21 \%$ of respondents reported that they have placebo preparations in their practice. However, some remarks on questionnaires and the interviews revealed that this includes saline preparations that, obviously, are available in any practice. To solve this problem, we now ask physicians to report the type of placebos they have in their practice. However, in general this block seems to be understood without any problems as physicians intuitively equate placebo or typical placebo with pure placebo.

Instead, terminological problems were obvious in block B (fig. $1 \mathrm{~B}$ ) concerning nonspecific treatments defined in the questionnaire as drugs or treatments that do not have any intrinsic effect on the illness of the patient or on the symptoms. This block comprises 3 questions: use, frequency of use in the last 12 months, and type of interventions used as nonspecific treatment (11 answer options; collection based on available surveys $[1,6])$. The cognitive interviews clearly confirmed that the concept of impure placebos is unfamiliar and confusing to physicians. Although several physicians used impure placebos as examples for placebo interventions in the course of the in-

\section{Block B: Use of non-specific treatments}

1. Have you ever used in your practice drugs or treatments even though you thought that these did not have any intrinsic effect against the illness of the patient or on its symptoms (e.g. antibiotics in a patient likely to suffer from a viral infection or a herbal remedy although you personally thought it is without effect on the specific symptoms)?

$$
\text { O yes } \quad \text { O no (please go to question 8) }
$$

2. Please give an estimate in how many patients you used such a non-specific treatment in the last 12 months?

in about___ patients in the last 12 months

3. What types of drugs/treatments have you already used as non-specific treatment? (check all that apply)

Please note that here we only ask for situations in which you personally thought that the treatment would have no intrinsic/specific effect on the symptoms, not the use of such treatments in general! O Micronutrients

O Vitamines

O Sedatives (e.g. zopiclon, opipramol, chloralhydrat)

$\mathrm{O}$ Antibiotics

O Analgesics or NSAIDs

O Drugs in subtherapeutic dosage

O Homeopathic remedies

O Herbal remedies

O Acupuncture

O Manual therapies

O Other:

Fig. 1 B. Use of nonspecific treatments

\begin{tabular}{|c|c|c|c|c|c|}
\hline \multicolumn{6}{|c|}{ Block C: Attitudes to and use of complementary therapies } \\
\hline \multicolumn{6}{|c|}{ Please mark on how you rate the following therapies regarding the clinical effects over placebo } \\
\hline & $\begin{array}{c}\text { Is a } \\
\text { placebo }\end{array}$ & \multirow{2}{*}{$\begin{array}{l}\text { Rather a } \\
\text { placebo } \\
\text { treatment }\end{array}$} & $\begin{array}{l}\text { Partly/ } \\
\text { don't }\end{array}$ & $\begin{array}{c}\text { Rather } \\
\text { more than }\end{array}$ & $\begin{array}{l}\text { Is more } \\
\text { than a }\end{array}$ \\
\hline & treatment & & know & a placebo & placebo \\
\hline 8. Acupuncture & $\mathrm{O}$ & $\mathrm{O}$ & $\mathrm{O}$ & $\mathrm{O}$ & $\mathrm{O}$ \\
\hline 9. Homeopathy & $\mathrm{O}$ & $\mathrm{O}$ & $\mathrm{O}$ & $\mathrm{O}$ & $\mathrm{O}$ \\
\hline 10. Osteopathy & $\mathrm{O}$ & $\mathrm{O}$ & $\mathrm{O}$ & $\mathrm{O}$ & $\mathrm{O}$ \\
\hline 11. Chirotherapy & $\mathrm{O}$ & $\mathrm{O}$ & $\mathrm{O}$ & $\mathrm{O}$ & $\mathrm{O}$ \\
\hline 12. Herbal remedies & $\mathrm{O}$ & $\mathrm{O}$ & $\mathrm{O}$ & $\mathrm{O}$ & $\mathrm{O}$ \\
\hline 13. Other naturopathic treatments & $\mathrm{O}$ & $\mathrm{O}$ & $\mathrm{O}$ & $\mathrm{O}$ & $\mathrm{O}$ \\
\hline 14. Vitamins/Micronutrients & $\mathrm{O}$ & $\mathrm{O}$ & $\mathrm{O}$ & $\mathrm{O}$ & $\mathrm{O}$ \\
\hline \multicolumn{6}{|c|}{ Please mark how often you use the following therapies in your practice } \\
\hline & Never & $\begin{array}{l}<1 \times \text { per } \\
\text { month }\end{array}$ & $\begin{array}{l}1-4 \times \text { per } \\
\text { month }\end{array}$ & $\begin{array}{l}>4 \times \text { per } \\
\text { month }\end{array}$ & Every day \\
\hline 15. Acupuncture & $\mathrm{O}$ & $\mathrm{O}$ & $\mathrm{O}$ & $\mathrm{O}$ & $\mathrm{O}$ \\
\hline 16. Homeopathic remedies & $\mathrm{O}$ & $\mathrm{O}$ & $\mathrm{O}$ & $\mathrm{O}$ & $\mathrm{O}$ \\
\hline 17. Osteopathy & $\mathrm{O}$ & $\mathrm{O}$ & $\mathrm{O}$ & $\mathrm{O}$ & $\mathrm{O}$ \\
\hline 18. Chirotherapy & $\mathrm{O}$ & $\mathrm{O}$ & $\mathrm{O}$ & $\mathrm{O}$ & $\mathrm{O}$ \\
\hline 19. Herbal remedies & $\mathrm{O}$ & $\mathrm{O}$ & $\mathrm{O}$ & $\mathrm{O}$ & $\mathrm{O}$ \\
\hline 20. Other naturopathic treatments & $\mathrm{O}$ & $\mathrm{O}$ & $\mathrm{O}$ & $\mathrm{O}$ & $\mathrm{O}$ \\
\hline 21. Vitamins/Micronutrients & $\mathrm{O}$ & $\mathrm{O}$ & $\mathrm{O}$ & $\mathrm{O}$ & $\mathrm{O}$ \\
\hline 22. Other complementary therapies: & $\mathrm{O}$ & $\mathrm{O}$ & $\mathrm{O}$ & $\mathrm{O}$ & $\mathrm{O}$ \\
\hline \multicolumn{6}{|c|}{$\begin{array}{l}\text { Are you certified for one of the following therapies or are you in the process of obtaining such } \\
\text { a certification? }\end{array}$} \\
\hline & \multicolumn{2}{|c|}{ I am certified for } & \multicolumn{2}{|c|}{$\begin{array}{l}\text { I am in the process of } \\
\text { obtaining th } \\
\text { certification for }\end{array}$} & Neither nor \\
\hline 23. Acupuncture & \multicolumn{2}{|l|}{$\mathrm{O}$} & \multicolumn{2}{|l|}{$\mathrm{O}$} & $\mathrm{O}$ \\
\hline 24. Homeopathy & \multicolumn{2}{|l|}{$\mathrm{O}$} & \multicolumn{2}{|l|}{$\mathrm{O}$} & $\mathrm{O}$ \\
\hline 25. Manual medicine/Chirotherapy & \multicolumn{2}{|l|}{$\mathrm{O}$} & \multicolumn{2}{|l|}{$\mathrm{O}$} & $\mathrm{O}$ \\
\hline 26. Naturopathy & \multicolumn{2}{|l|}{$\mathrm{O}$} & \multicolumn{2}{|l|}{$\mathrm{O}$} & $\mathrm{O}$ \\
\hline 27. Other: & \multicolumn{2}{|l|}{$\mathrm{O}$} & $\mathrm{O}$ & & \\
\hline 28. Andere: & $\mathrm{O}$ & & $\mathrm{O}$ & & \\
\hline
\end{tabular}

Fig. 1 C. Attitudes to and use of complementary therapies. 


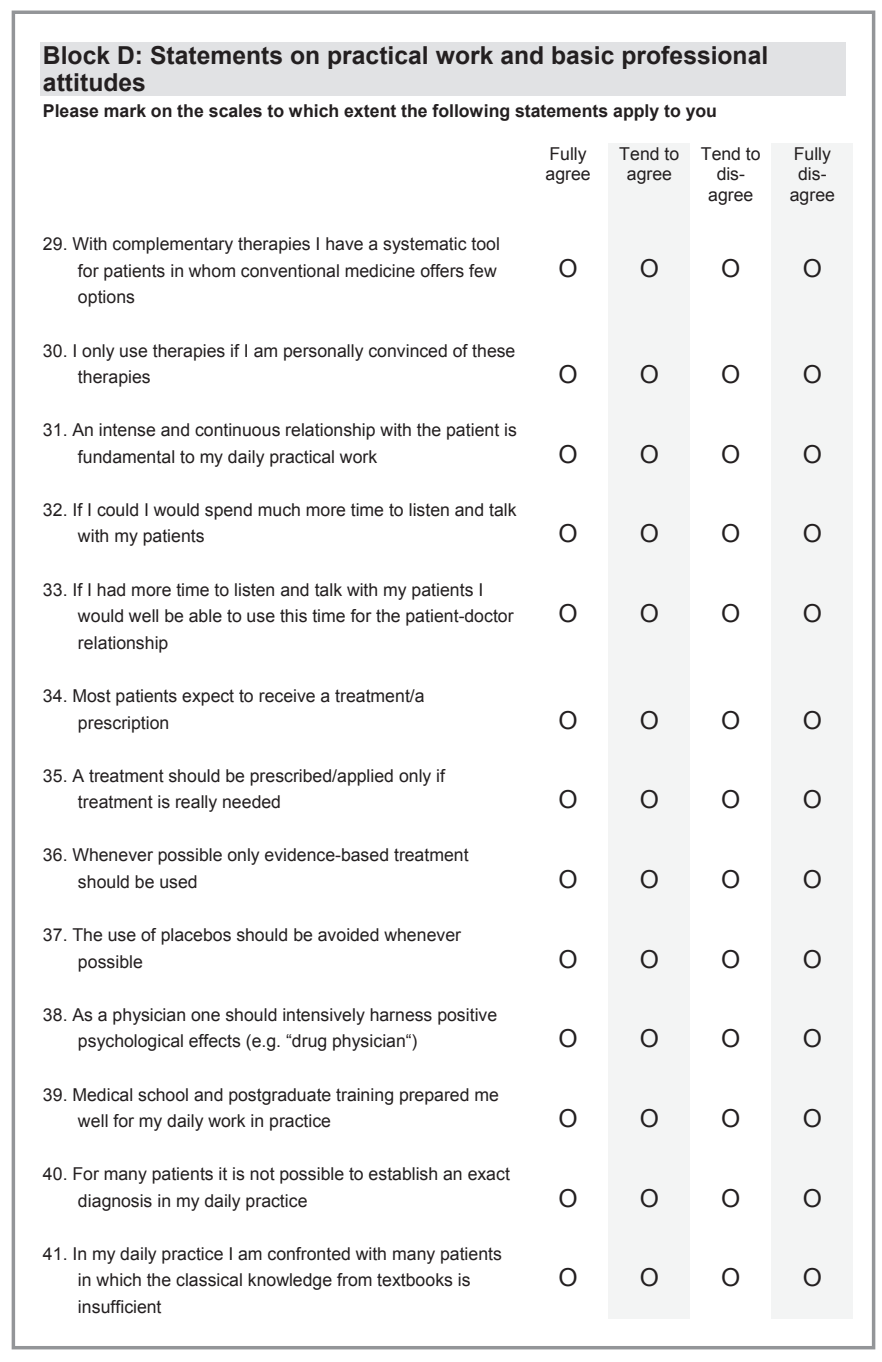

Fig. 1 D. Statements on practical work and basic professional attitudes.

terviews themselves, the term placebo was always associated primarily with pure placebos. The term nonspecific treatment was considered more familiar, but still difficult. There were considerable discussions on how to best paraphrase and explain nonspecific treatments but no solution seemed optimal. The example of applying antibiotics in case of a patient likely to suffer from a viral infection was obvious to all interviewed GPs and internists, but not to the orthopedists (therefore another example was chosen for this group). However, these terminological issues did not seem to create major problems in understanding the questions in principle and to answer them in a relatively straightforward way. Still, while our wording in this block seems to be understood in general it is clear that there is some ambiguity remaining and room for interpretation to the physicians.

Block C (fig. 1 C) includes 21 questions concerning the attitudes toward and the use of complementary therapies. First, physicians are asked to mark on a 5-point scale whether they consider 7 listed complementary therapies widespread in Germany to be more effective than placebo. In the following ques-

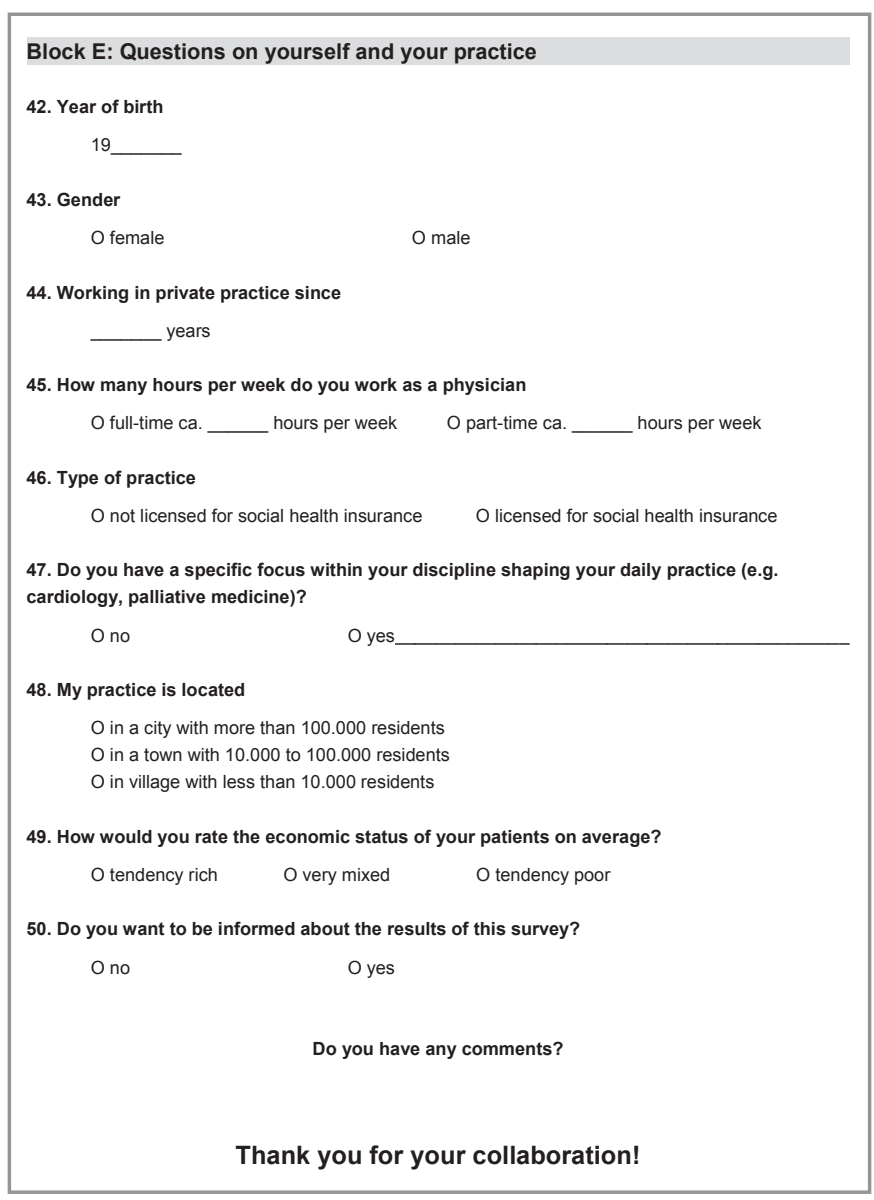

Fig. 1 E. Questions on yourself and your practice.

tions physicians are asked to indicate how often they use these 7 therapies (with an additional possibility to report other complementary therapies not mentioned). Finally physicians are asked whether they hold certificates for the 4 complementary therapies officially accredited by the German Medical Association; the possibility to indicate 2 other treatments is also given. These questions were understood and answered without any relevant problem.

Block D (fig. $1 \mathrm{D}$ ) comprises 13 statements on practical work and basic professional attitudes. Physicians are asked to indicate the level of agreement on a 4-point scale. The statements are mainly based on the theoretical considerations summarized above and in other publications [20]. Pilot testing and cognitive interviews revealed considerable problems with the understanding of several important statements included in the initial version of the questionnaire. We had tried to confront physicians immediately and directly with the key statement 'a treatment should only be prescribed or applied if it is necessary and effective (beyond a placebo effect)' based on the findings by Comaroff summarized above [7]. There was only one missing answer in the pretest. Answers varied strongly ( $22 \%$ fully agreed, $54 \%$ tended to agree, $15 \%$ tended to disagree, and $9 \%$ fully disagreed) indicating that either Comaroff's 
conclusion is wrong or that the question was not understood. The cognitive interviews strongly suggest that probably many physicians answered in a manner that already reflected the tension between the ideal (to which they agreed in principle) and what is realistic in practice. Regarding a related question one internist said: 'Everyone who reflects his work somewhat critically, who thinks a bit about himself, he will not be able to give an absolute answer here. He will rate somewhere in the middle...'. Furthermore, it was unclear what was considered effective compared to placebo and whether it was related to personal belief or scientific proof. Thus we gave up the idea of investigating whether the doctors agree with the implicit professional ideals. In the final version the statement is separated into 2 statements and instead of speaking of effects over placebo we use the wording 'evidence-based treatments'. In general, physicians had little problems to mark their answers in this section, but the interviews made clear that the complexity of the issues addressed could not be fully grasped in the statements, and that there is considerable room for subjective interpretation. It seems unlikely that this could be improved fundamentally in the final version although we did our best. Therefore, the findings related to this section will have to be interpreted with caution.

Finally Block E (fig $1 \mathrm{E}$ ) documents basic information on the physicians (birth year, gender, working experience, type of practice, specialties, location, and average economic status of patients) and whether physicians want to be informed about the results of the survey.

\section{Discussion}

Based on a review of the available literature [1], own experience in surveys, and against the background of theoretical considerations we have systematically developed a 4-page questionnaire to collect reliable data on the use of placebos as well as nonspecific and complementary treatments and their relation to basic professional attitudes among physicians in Germany. We are aware that particularly the use of nonspecific treatments and basic professional attitudes are difficult to investigate with a standardized questionnaire. The results obtained (as those of previous surveys) will have to be considered with caution due to the unavoidable terminological ambiguities. We did not run another pretest after revising the questionnaire based on the interviews as resources were limited, most changes were minor, and a quantitative pretest seemed inappropriate to check whether the major changes in the statements on basic professional attitudes led to noticeable improvements. We want to emphasize that our questionnaire might not be easy to apply in other countries where the use of complementary treatments by physicians is less frequent.

Our survey differs considerably from most available quantitative surveys. On the one hand, a main focus of our survey is the emphasis on basic professional attitudes and the link between placebo and complementary and alternative medicine. On the other hand, we do not ask how physicians practically apply pure placebos and nonspecific interventions, why such interventions are used, and what physicians tell patients in these instances.

Our survey is currently (January 2013) in the data collection phase. Questionnaires have been sent to each 700 GPs, internists, and orthopedists randomly selected from a commercially available address database which covers more than $80 \%$ of physicians working in private practice in Germany. Physicians not responding to the first contact receive up to 2 reminders. Postal surveys among physicians often suffer from very low response rates [21]. Unfortunately, we were unable to obtain funding to include an nonbinding incentive (a book voucher of EUR 10) in the first letter, as there is good evidence that this single measure is highly effective in increasing response rate $[21,22]$. In our cognitive interviews we also asked the physicians whether they would fill out the questionnaire if they found it in their mail and how to increase chances of response. All interviewed physicians agreed that the letter should clearly state that the survey is the basis for a medical thesis (it must kept in mind, however, that the interviewer was a doctorate candidate) as most physicians remember how much they depended on others when they did their own thesis. We consider a response rate of $40 \%$ as a realistic target but hope to receive an even higher result.

While quantitative surveys on this topic are relevant it is obvious that more qualitative studies are needed to really understand when, how, and why placebos and nonspecific treatments are used in routine practice. Interviewing physicians individually and focusing group discussions are logical first steps, but what physicians think and say might not fully indicate what they actually do. Therefore, direct observation of practice might be necessary at some point.

We are confident that our survey will provide solid findings about the frequency of the use of pure and impure placebo interventions in Germany and its association with attitudes toward the use of complementary therapies. We hope that we also will get some insights regarding the relation between basic professional attitudes and placebo use.

\section{Acknowledgement}

We would like to thank the physicians participating in the cognitive interviews.

\section{Disclosure Statement}

The authors declare that there is no conflict of interests concerning this paper. 


\section{References}

1 Fässler M, Meissner K, Schneider A, Linde K: Frequency and circumstances of placebo use in clinical practice - a systematic review of empirical studies. BMC Med 2010;8:15.

2 Louhiala P: What do we really know about the deliberate use of placebos in clinical practice? J Med Ethics 2012;38:403-405.

3 Bundesärztekammer (ed): Stellungnahme 'Placebo in der Medizin'. Köln, Deutscher Ärzte-Verlag, 2011.

4 Lange HU: Zur Praxis der Placebobehandlung in einer psychiatrischen Klinik. Psychiat Prax 1981;8: 147-151.

$\checkmark 5$ Bernateck M, Karst M, Eberhard S, Vivell W, Fischer MJ, Stichtenoth DO: Placebotherapie: Analyse von Umfang und Erwartung in einer Klinik der Maximalversorgung. Schmerz 2009;23:47-53.

6 Meissner K, Höfner L, Fässler M, Linde K: Widespread use of pure and impure placebo interventions by GPs in Germany. Fam Pract 2012;29:79-85.

7 Comaroff J: A bitter pill to swallow: placebo therapy in general practice. Sociol Rev 1976;24:79-96.

8 Henriksen K, Hansen EH: The threatened self: general practitioners' self-perception in relation to prescribing medicine. Soc Sci Med 2004;59:47-55.

$\checkmark$ Weiss MC, Scott D: Whose rationality? A qualitative analysis of general practitioners' prescribing. Pharm J 1997;259:339-341.
10 Butler CC, Rollnick S, Pill R, Maggs-Rapport F, Stott N: Understanding the culture of prescribing: qualitative study of general practitioners' and patients' perceptions of antibiotics for sore throats. BMJ 1998:317:637-642.

11 Kumar S, Little P, Britten N: Why do general practitioners prescribe antibiotics for sore throat? Grounded theory interview study. BMJ 2003;326:138.

12 Hrobjartsson A, Norup M: The use of placebo interventions in medical practice - a national questionnaire survey of Danish clinicians. Eval Health Prof 2003;26:153-165.

13 Fässler M, Gnadinger M, Rosemann T, BillerAndorno N: Use of placebo interventions among Swiss primary care providers. BMC Health Serv Res 2009;9:144.

14 Kermen R, Hickner J, Brody H, Hasham I: Family physicians believe the placebo effect is therapeutic but often use real drugs as placebos. Fam Med 2010; 42:636-642.

15 O'Riordan M, Dahinden A, Aktürk Z, Ortiz JM, Dağdeviren N, Elwyn G, Micallef A, Murtonen M, Samuelson M, Struk P, Tayar D, Thesen J: Dealing with uncertainty in general practice: an essential skill for the general practitioner. Qual Prim Care 2011;19:175-181.
16 Morris CJ, Cantrill JA, Weiss MC: GPs attitudes to minor ailments. Fam Pract 2001;18:581-585.

17 Tilscher H: Konservative Orthopädie - Manuelle Medizin. Mehr als nur eine mögliche Vernunftehe? Manuelle Medizin 2006;44:171-176.

18 Fent R, Rosemann T, Fassler M, Senn O, Huber CA The use of pure and impure placebo interventions in primary care - a qualitative approach. BMC Fam Pract 2011;12:11.

19 Willis G: Cognitive Interviewing: A Tool for Improving Questionnaire Design. Thousand Oaks, Sage, 2005 .

20 Linde K, Fässler M, Meissner K: Placebo interventions, placebo effects and clinical practice. Philos Trans R Soc Lond B Biol Sci 2011;366:1905-1912.

21 VanGeest JP, Johnson TP, Welch VL: Methodologies for improving response rates in surveys of physicians: a systematic review. Eval Health Prof 2007; 30:303-321.

22 Edwards PJ, Roberts I, Clarke MJ, Diguiseppi C, Wentz R, Kwan I, Cooper R, Felix LM, Pratap S: Methods to increase response to postal and electronic questionnaires. Cochrane Database Syst Rev 2009;8:MR000008 